\section{CONTRIBUIÇĀO AO ESTUDO DA INERVAÇĀO DO DIAFRAGMA EM EQÜINOS DA RAÇA PURO SANGUE INGLÊS}

\author{
WILSON SANTIAGO \\ Professor Assistente \\ Centro de Ciências Biológicas e de Saúde \\ Universidade Federal de Viçosa - MG \\ JOĀO GI LBERTO LOPES PEREIRA \\ Professor Livre Docente
}

Faculdade de Medicina Veterinária e Zootecnia da USP

SANTIAGo, W. \& PEREIRA, J.G.L. Contribuição ao estudo da inervação do diafragma em equinos da raça Puro Sangue Inglês. Rev. Fac.Mec.vet Zootec.Univ.S.Paulo, 20(2): 143-53, 1983.

RESUMO: Os resultados ob tidos com o estudo de 30 diafragmas de cavalos da raça Puro Sangue Inglès, adultos, retirados de 15 machos e 15 fèmeas, oriundos do Jockey Clube de São Paulo e Jockey Clube Brasileiro, permitiram-nos chegar à seguintes conclus żes: 1) os nervos frénicos terminam em ramo ventral e tronco dorsdateral à direita $(96,7 \%)$ e à esquerda $(26,7 \%)$, ou em ramo dorsal e tronco ventrolateral à esquerda $(66,7 \%)$ e à direita $(3,3 \%)$, encontrando-se ainda, trifurcação em ramos dorsal, la teral e ventral à esquerda $(6,6 \%)$. Os nervos frènicos direito e esquerdo comportam-se simetricamente em ramo ventral e tronco dorsolateral $(26,7 \%)$ e, em ramo dorsal e tronco ventrolateral $(3,3 \%) ; 2)$ os ramos dorsais dos nervos frènicos inervam a esquerda $(86,6 \%)$ e à direita $(83,3 \%)$ a parte lombar do mesmo lado; fornecem filetes ao centro tendíneo do diafragma, tan to à direita como à esquerda $(6,6 \%)$; emitem filetes ao follolo dorsal à direita $(6,6 \%)$; a parede da veia cava caudal à esquerda $(6,6 \%)$; e, em apenas urra oportunidade, enviam ramos à porçāo lombar direita $(3,3 \%) ; 3)$ os ramos laterais dos nervos frénicos inervam à esquerda $(90,0 \%)$ e à direita $(56,6 \%)$ a parte costal, mais precisamente, as porç öes dorsal e lateral; à direita $(23,3 \%)$ emitem filetes à porçāo lombar; enviam filetes ao folíolo dorsal à direita $(20,0 \%)$ e à esquerda $(3,3 \%)$; $\theta$, dirigem-se à porção verm ral do parte costal à esquerda $(6,6 \%)$ 4) os ramos ventrais dos nervos frênicos inervam à esquerda $(86,6 \%)$ e à direita $(76,6 \%)$ a porça ão ventral da parte costal e a parte estemal do mesmo lado; enviam ramos ao follolo ventral à direita e à esquerda $(6,6 \%)$; atravessam o fol folo ventral, sendo o responsável pela inervação da parte estemal heterónima à esquerda $(3,3 \%)$ inervam somente a porção ventral da parte costal à direita $(3,3 \%)$; constituem pequeno tronco que se desdobra em dois filetes, um à porção ventral da parte costal e outro à parte esternal, à direita $(3,3 \%)$; emitem ramos ao folíolo dorsal à diraita $(3,3 \%)$; enviam filetes à perede da veia cava caudal a direita $(3,3 \%)$; emitem ramo que se endereça ao centro tendíneo do diafragma a direita $(3,3 \%)$; 5) conexöes ("anastomoses") homolaterais foram vistas à direita $(40,0 \%)$ e à esquerda $(3,3 \%)$, entre $\propto$ filetes: dos ramos dorsal direito e lateral direito $(30,0 \%)$, do ramo dorsal direito $(3,3 \%)$, do ramo lateral direito $(3,3 \%)$, do ramo ventral direito $(3,3 \%)$, e dos ramos dorsal esquerdo e lateral esquerdo $(3,3 \%) ; 6)$ a análise estatística não apresenta diferença significante, ao nfvel de $5,0 \%$, no tocante as várias modalidades de inervação do músculo dia fragma, quando confromados os sexos.

UNITERMos: Anatomia, eqüinos"; Diafragma*; Nervo frènico*

\section{INTRODUÇÃO E LITERATURA}

A importância do cavalo de raça Puro Sangue Inglès, como animal de esporte e de interesse econômico, bem como a constante busca de seu aprimoramento zootécnico. vem despertando grande atenção por parte dos pesquisadores, gerando assim, inúmeros trabalhos sobre diferentes aspectos do assunto.

Nesta oportunidade, propomo-nos a estudar a divisão e distribuição, no diafragma, do nervo frênico em tais eqüídeos, procurando melhor conhecer sua morfologia e, também, fomecer dados de proveito à Anatomia Comparativa.

Ainda mais, na literatura clássica consultada, poucos e genéricos são os dados fornecidos sobre 0 aludido as. sunto. De fato, BOSSI e colab. ${ }^{2}$, GURLT'S 8 , LESBRE 9. ELLENBERGER e BAUM 5, BRUNI e ZIMMERL 3, ZIMMERL 13 e GONZALEZ Y GARCIA e GONZALEZ ALVAREZ 7 , relatam que os nervos frênicos atingem o centro frénico onde se dividem e subdividem em ramos que se distribuem à porção carnosa. Devemos ressaltar, ainda, os relatos de BOSSI e colab. ${ }^{2}$, LESBRE 9 e BRUNI e ZIMMERL 3 que descrevem a existència de pequenos filetes endereçados aos pilares. Todavia, SISSON e GROSSMANN 12, SCHWARZE e SCHRODER 11 e GETTY 6 citam que os aludidos nervos se distribuem de forma radiada em direção à porção carnosa, ou, como salientam DOBBERSTEIN e HOFFMANN 4 e GETTY 6 , que os referidos nervos se ramificam no diafragma constituindo a inervação motora.

No tocante à literatura especializada, atinente ao focado assurto, PANCRAZI 10, estudando a disposicão do nervo frênico e suas divisões em boi, cavalo, cobaia, coelho, cão e gato, afirma que os contingentes nervosos principais são em número de très, denominando-os de ramo ventral, ramo lateral e ramo dorsal, sendo que o ventral inerva a região esternal e segmento da região costal; - lateral destina-se à porção restante da região costal; e o dorsal dirige-se à região lombar. Relata ainda, que alguns filetes provenientes do ramo dorsal esquerdo atingem o pilar direito do órgão, o que não ocorre no cão. O A. esclarece que a divisão varia segundo a espécie, e entre representantes da mesma espécie. 


\section{MATERIALE METODO}

Utilizamos para a presente pesquisa, 30 diafragmas de cavalos da raça Puro Sangue Inglês, 15 machos e 15 fêmeas, adultos, provenientes do Jockey Clube de São Paulo e Jockey Clube Brasileiro.

Uma vez aberta a cavidade abdominal, incisamos o diafragma próximo as suas inserções, mantendo em posição os segmentos do esòfago, aorta e veia cava caudal em suas passagens pelos respectivos hiatos e seccionamos os nervos frênicos a aproximacamente $10 \mathrm{~cm}$ de suas divisōes. As peças, assim isoladas, foram dissecadas após fixação, durante 48 horas em solução aquosa de formol a $10 \%$.

Colhemos desenhos esquemáticos das preparações, com vistas à descriç̧o dos resultados e ulterior documentaçảo, adotando-se, para o relato dos mesmos, a nomenclatura utilizada por BERTELLI 1.

Para a análise estatística dos dados, empregamos o teste do $X^{2}$.

\section{RESLILTADOS}

1) Ramos terminais do nervo frénico direito

a) Em 29 vezes $(96,7 \% \pm 3,3$ - Fig. 2 a 5), notamos o nervo frénico direito dividindo-se em ramo ventral e tronco dorsola teral.

b) Em 1 peça $(3,3 \% \pm 3,3-F$ ig. 1), patenteamos o nervo frênico direito terminando em ramo dorsal e tronco ventrolateral.

\section{2) Ramos terminais do nervo frênico esquerdo}

a) Em 20 casos $(66,7 \% \pm 8,6$ - Fig. 1, 3, 4) verificamos o nervo frênico esquerdo resolvendo-se em ramo dorsal e tronco ventrolateral.

b) Em 8 diafragmas $(26,7 \% \pm 7,7$ - Fig. 5), surpreendemos o nervo frênico esquerdo bifurcando-se em ramo ventral e tronco dorsolateral.

c) Em apenas 2 músculos $(6,7 \% \pm 4,5$ - Fig. 2). assinalamos o nervo frênico esquerdo trifurcando-se em ramo dorsal, lateral e ventral.

\section{3) Distribuição do ramo dorsal do nervo frênico direito}

a) Em 25 disseccōes $(83,3 \% \pm 6,8$ - Fig. 3 a 5) deparamos com o ramo dorsal direito dispondo-se somente na parte lombar direita do diafragma.

b) Em 2 preparações $(6,6 \% \pm 4,5$ - Fig. 1) encontramos o ramo dorsal direito distribuindo-se na parte lombar direita e emitindo um ou dois (Fig. 1) filetes nervosos para o centro tendineo do órgão. c) Em 1 arranjo $(3,3 \% \pm 3,3)$ registramos o ramo dorsal direito inervando a parte lombar direita e originando filete nervoso que se dirige ao folíolo dorsal direito.

d) Em 1 dissecçao $(3,3 \% \pm 3,3)$ registramos o ramo dorsal direito terminando na parte lombar direita e emitindo ramo para a porção lombar direita e dois filetes nervosos para o foll lolo dorsal.

e) Em 1 peça $(3,3 \% \pm 3,3$ - Fig. 2) reconhecemos o ramo dorsal direito emitindo ramo para a porção lombar direita e dois filetes nervosos que se destinam ao centro tendíneo do diafragma.

\section{4) Distribuição do ramo lateral do nervo frènico direito}

a) Em 17 vezes $(56,6 \% \pm 9,1-F$ ig. 4) vimos o ramo lateral direito resolvendo-se somente na parte costal direita, mais exatamente, nas porções dorsal e lateral.

b) Em 6 casos $(20,0 \% \pm 7,3)$ identificamos o ramo lateral direito, além de inervar as porçōes dorsal e lateral da parte costal, a emitir pequeno ramo para a porção lombar direita do músculo.

c) Em 5 dissecços $(16,6 \% \pm 6,8$ - Fig. 1, 2, 5) evidenciamos o ramo lateral direito inervando as porções dorsal e lateral da parte costal e emitindo um ( $F$ ig. 5) ou dois (Figs. 1 e 2) filetes nervosos em direção ao follolo dorsal direito.

d) Em 2 preparações (6,6\% $\pm 4,5$ - Fig. 3) notamos - ramo lateral direito inervando as porções dorsal e lateral da parte costal e emitindo pequeno tronco, dividindo-se em um ramo para o folfolo dorsal direito e outro à porção lombar direita do órgão (Fig. 3) e dois filetes nervosos isolados que se dirigem, um ao follolo dorsal direito e outro à porçåo lombar direita do diafragma.

5) Distribuição do ramo ventral do nervo frênico direito

a) Em 23 dissecções $(76,6 \% \pm 7,7$ - Fig. 1, 3, 5) patenteamos o ramo ventral direito dispondo-se na porçåo ventral da parte costal direita e na parte esternal do mesmo lado.

b) Em 3 vezes $(10,0 \% \pm 5,5$ - Fig. 2, 4) verificamos o ramo ventral direito inervando a porçăo ventral da parte costal direita e parte esternal direita, emitindo ainda pequeno ramo para o foliolo ventral ( $F$ ig. 2) ou em direçăo ao follolo dorsal (F ig. 4).

c) Em 1 peça $(3,3 \% \pm 3,3)$ surpreendemos o ramo ventral direito distribuindo-se na porçăo ventral da parte costal direita e parte esternal direita, e a emitir pequeno tronco que se bifurca, originando dois filetes que se dirigem, um à parede da veia cava caudal e outro ao centro tendíneo do músculo.

d) Em 1 caso $(3,3 \% \pm 3,3)$ assinalamos o ramo ventral direito inervando a porçäo ventral da parte costal direita 
e parte esternal direita, emitindo filete nervoso em direção à parede da veia cava caudal.

e) Em 1 preparação $(3,3 \% \pm 3,3)$ deparamos com o ramo ventral direito desdobrando-se em um ramo para a região ventral da parte costal direita e outro para a porção esternal do mesmo lado.

f) Em 1 arranjo $(3,3 \% \pm 3,3)$ encontramos o ramo ventral direito resolvendo-se apenas na porção ventral da parte costal direita.

\section{6) Distribuição do ramo dorsal do nervo frênico esquerdo}

a) Em 26 órgðos $(86,6 \% \pm 6,2$ - Fig. $1,2,4,5)$ vimos - ramo dorsal esquerdo dispondo-se somente na parte lombar esquerda do diafragma.

b) Em 2 vezes $(6,6 \% \pm 4,5$ - Fig. 3) reconhecemos - ramo dorsal esquerdo distribuindo-se na parte lombar esquerda e emitindo pequeno ramo que se dirige à parede da veia cava caudal.

c) Em 2 peças $(6,6 \% \pm 4,5)$ identificamos o ramo dorsal esquerdo inervando a parte lombar esquerda e originando filete nervoso que se dirige ao centro tend rneo do músculo.

7) Distribuição do ramo lateral do nervo frènico esquerdo

a) Em 27 casos $(90,0 \% \pm 5,5$ - Fig. 1 a 5$)$ eviden. ciamos o ramo lateral esquerdo resolvendo-se somente na parte costal esquerda, mais precisamente, nas porçōes dorsal e lateral.

b) Em 2 preparações $(6,6 \% \pm 4,5)$ notamos o ramo lateral esquerdo na porção costal esquerda, mais exatamente, nas porções dorsal, la teral e ventral.

c) Em 1 arranjo $(3,3 \% \pm 3,3)$ patenteamos o ramo lateral esquerdo emitindo pequeno ramo para o foliolo dorsal esquerdo, além de inervar as porções dorsal e lateral da parte costal.

8) Distribuição do ramo ventral do nervo frênico esquer do

a) Em 26 vezes $(86,6 \% \pm 6,2$ - Fig. 1 a 5$)$ verificamos - ramo ventral esquerdo dispondo-se na porção ventral da parte costal esquerda e na parte esternal do mesmo lado.

b) Em 2 peças $(6,6 \% \pm 4,5)$ surpreendemos o ramo ventral esquerdo distribuindo-se na porção ventral das partes costal e esternal esquerda, além de emitir filete nervoso para o fol iolo ventral.

c) Em 1 músculo $(3,3 \% \pm 3,3)$ assinalamos o ramo ventral esquerdo inervando apenas a parte esternal esquerda.

d) Em 1 dissecção $(3,3 \% \pm 3,3)$ encontramos o ramo ventral esquerdo resolvendo-se na porção ventral da parte costal esquerda e na parte esternal do mesmo lado, além de emitir ramo que atravessa o folíolo ventral e se dirige para a parte esternal direita.

9) Conexōes ("anastomoses") entre os ramos terminais dos nervos frènicos

a) Em 6 casos $(20,0 \% \pm 7,3$ - Fig. 1, 4) deparamos com "anastomoses" entre filetes dos ramos dorsal direito e lateral direito, sendo que, em uma oportunidade ( $F$ ig. 1), vimos duas conexões entre os citados ramos.

b) Em 3 preparaçöes $(10,0 \% \pm 5,5-F i g .3)$ reconhecemos "anastomoses" entre o ramo dorsal direito e fila mento oriundo do ramo lateral direito, encarregado da inervação parcial da porção lombar direita. Cabe ressaltar que em um arranjo (Fig. 3 ) identificamos duas conexöes entre as aludidas entidades.

c) Em 1 órgão (3,3\% $\pm 3,3)$ evidenciamos "anastomoses" entre filete do ramo lateral direito e filete proveniente do ramo lateral direito que se dirige à porção lombar direita.

d) Em 1 vez $(3,3 \% \pm 3,3)$ notamos "anastomose" entre filetes do ramo ventral do nervo frènico direito.

e) Em 1 peça $(3,3 \% \pm 3,3$ - Fig. 2) patenteamos "anastomose" entre filetes do ramo dorsal do nervo frênico direito.

f) Em 1 caso (3,3\% $\pm 3,3$ - Fig. 5) verificamos "anas. tomose" envolvendo filetes dos ramos dorsal esquerdo e lateral do mesmo lado.

Analisando estatisticamente os dados atinentes à distribuição dos ramos dos nervos frênicos na inervação do diafragma, verificamos que, ao nivel de $5,0 \%$, as diferenças rela tivas ao sexo não são significantes.

\section{COMENT ÃRIOS E CONCLUSÕES}

Ao examinarmos os tratados no tocante à divisão terminal dos nervos frênicos no eqüino, BOSSI e colab. ${ }^{2}$, GURLT'S 8, LESBRE 9, ELLENBERGER e BAUM 5, BRUNI E ZIMMERL 3, ZIMMERL 13, GONZALEZ Y GARCIA \& GONZALEZ ALVAREZ ?. SISSON GROSSMAN 12 , SCHWARZE E SCHRODDER 11 , GETTY 6 e, DOBBERSTEIN e HOFFMANN 4 , lemos que os aludidos nervos, ao atingirem o centro frênico do diafragma, dividem-se e subdividem-se em filetes nervosos, para alcançar a porção carnosa, disposição observada também, em cavalos da raça Puro Sangue Inglês.

Já, PANCRASI 9, estudando os ramos terminais do nervo frènico, encontra très, denominando-os de ramo ventral, ramo lateral e ramo dorsal, modalidade que por vezes $(6,6 \%)$ encontramos e descrevemos como trifurcação.

Com base nos achados e na nomenclatura estabelecida por BERTELLI 1, no atinente à divisão terminal dos 
nervos frênicos, anotamos dois tipos de bifurcação tanto à direita quanto à esquerda e um de trifurcação à esquer. da. O nervo frènico direito termina em ramo ventral e tronco dorsolateral $(96,7 \%)$, e ramo dorsal e tronco ventrolateral $(3,3 \%)$, arranjos a que todos os $A A$. anteriormente citados não aludem. À esquerda, assinalamos também dois tipos de bifurcação, em ramo dorsal e tronco ventrolateral $(66,7 \%)$, e ramo ventral e tronco dorsolateral $(26,7 \%)$ e tifurcação em ramos dorsal, lateral e ventral $(6,6 \%)$. Verificamos simetria bilateral, quando os aludidos nervos cedem os ramos ventral e tronco dorsolateral $(26,7 \%)$, e o ramo dorsal e tronco ventrolateral $(3,3 \%)$.

Atentando, agora, para a distribuição dos nervos frênicos, os ramos dorsais inervam a parte lombar do mesmo lado, à esquerda $(86,6 \%)$ e à direita $(83,3 \%)$, fato este que concorda parcialmente comPANCRAZI 10 , que $n$ ão identificou as demais modalidades de inervação por nós observadas nos animais P.S.I. No tocante aos ramos laterais que inervam as partes costais esquerda e direita $(50,6 \%)$, mais precisamente as porções dorsal e lateral, os AA. consultados não fazem menção a nenhum outro dipo de comportamento por nós observado. Da mesma forma, os ramos ventrais, à esquerda $(86,6 \%)$ e à direita $(76,6 \%)$ inervam a porção ventral da parte costal e parte esternal do lado correspondente, fato este que não coincide com as descrições exaradas por PANCRAZI 10.

Cabe ainda ressaltar que, relativamente aos cavalos P.S.I., verificamos a presença de filetes oriundos dos ramos dorsais, a dirigirem-se para o centro tendíneo do diafragma em ambos os lados $(6,6 \%)$; à parede dorsal da veia cava caudal, à esquerda $(6,6 \%)$; à porção lombar direita $(3,3 \%)$. Assinalamos, também, alguns filetes procedentes dos ramos laterais atingindo a porção lombar direita $(23,3 \%)$; os fol íolos dorsais à direita $(20,0 \%)$ e à esquerda $(3,3 \%)$; a porção ventral da parte costal à esquerda $(6,6 \%)$. Surpreendemos, ainda, filetes provenientes dos ramos ventrais, inervando os foliolos ventrais de ambos os lados $(6,6 \%)$; a porção esternal à esquerda $(3,3 \%)$; a porção ventral da parte costal à direita $(3,3 \%)$; as porções ventral da parte costal e parte esternal à direita $(3,3 \%)$; a parede da veia cava caudal à direita $(3,3 \%)$; e, o centro tendi neo à direita $(3,3 \%)$.

Registramos conex ões ("anastomoses"), sempre homolaterais, à direita $(40,0 \%)$ e à esquerda $(3,3 \%)$, vale dizer, envolvendo filete: dos ramos dorsal e lateral direitos $(30,0 \%)$; apenas do ramo dorsal direito $(3,3 \%)$; unica- mente do ramo lateral direito $(3,3 \%)$; somerte to ramo ventral direito $(3,3 \%)$; dos ramos dorsal e lateral esquerdo $(3,3 \%)$.

SANTIAGO, W. \& PEREIAA, J.G.L. Contribution to the study on the innervation of the diaphragm in throughbred horses. Rov. Fac.Med.vet.Zootec.Univ.S.Paulo, 20(2): 143-53, 1983.

SUMMARY: The results obtained through the study of 30 diaphragms of adult throughbred horses, extracted from 15 male and 15 female animals from the Jockey Clube de São Paulo and the Jockey Clube Brasileiro, allowed us to come to the following conclusions: 1) The phrenic nerves terminate in a ventral branch and in a dorsolateral trunk on the right $(96.7 \%)$ and on the left $(26.7 \%)$, or in a dorsal branch and a ventrolateral trunk on the left $(66.7 \%)$ and on the right (3.3\%). Trifurcations in ventral, lateral and dorsal branches are also found on the left $(6,6 \%)$. Right and left phrenic nerves are simetrically arranged in a ventral branch and a dorsolateral trunk (26.7\%) and a dorsal branch and a ventrolateral trunk (3.3\%). 2) The dorsal branches of the phrenic nerves innervate the lumbar portion on the left $(86.6 \%$ ) and on the right $(83.3 \%)$ respectively. They provide fillets to the tendinous center of the diaphragm either on the right or on the left (6.6\%). They also provide fillets to the dorsal (enflet on the right $(6.6 \%)$, and to the vena cava cauchl on the left (6.6\%), and only in one case they provide branches to the right lumbar portion (3.3\%). 3) The lateral branches of the phrenic innervate the costal portion on the left $(90.0 \%)$ and on the right $(56.6 \%)$, more precisely the dorsal and lateral portion. They provide fillets to the dorsal leaflet on the right $(20.0 \%)$ and on the left $(3.3 \%)$, they go towards the ventral portion of the costal part on the left $(6.6 \%)$. 4) The ventral branches of the phrenic nerves innervate the ventral portion of the costal part and the sternal part on the left $(86.6 \%)$ and on the right $(76.6 \%)$, respectively. They send branches to the ventral leaflet on the right and on the left $16.6 \%)$. They transverse the ventral leaflet which is responsable for the innervation of the heteronomous stemal part on the left $13.3 \%)$. They innervate only the ventral portion of the costal part on the right (3.3\%). They form a small trunk which extends into two fillets, one to the ventral portion of the costal part, and other to the stemal part of the right $(3.3 \%)$. They also send branches to the dorsal leaflet of the right $(3.3 \%)$. They send fillets to the wall of vena cava caudal on the right $(3.3 \%)$. They send a branch which goes to the tendinous center of the diaphragm on the right $(.33 \%)$. 5) The homolateral conexions ("anastomosis") were found on the right $(40.0 \%)$ and on the left (3.3\%) among the following fillets* of the right dorsal and lateral branches $(30.0 \%)$ af the right lateral branch $(3.3 \%)$, of the right ventral branch $(3.3 \%$; and of the left lateral and dorsal branches $(3.3 \%) .6)$ The statistical analysis does not show a significant difference, at the level of $5.0 \%$, conceming several aspects of innervation of the diaphragmaric muscles, when both sexes are compared.

UNITERMS: Anatomy of horse*: Diaphragm *; Phrenic nerve* 
Esquema da divisão e distribuição dos nervos frénicos no diafragma (face tor ácica) de cavalos da raça Puro Sangue Inglês.

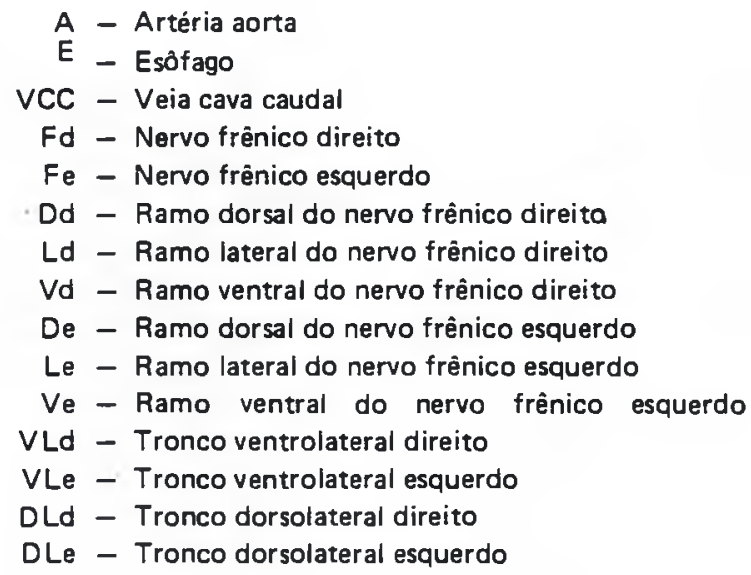

Recebido em: 10-08-83

Aprovado em: 15-03-84 


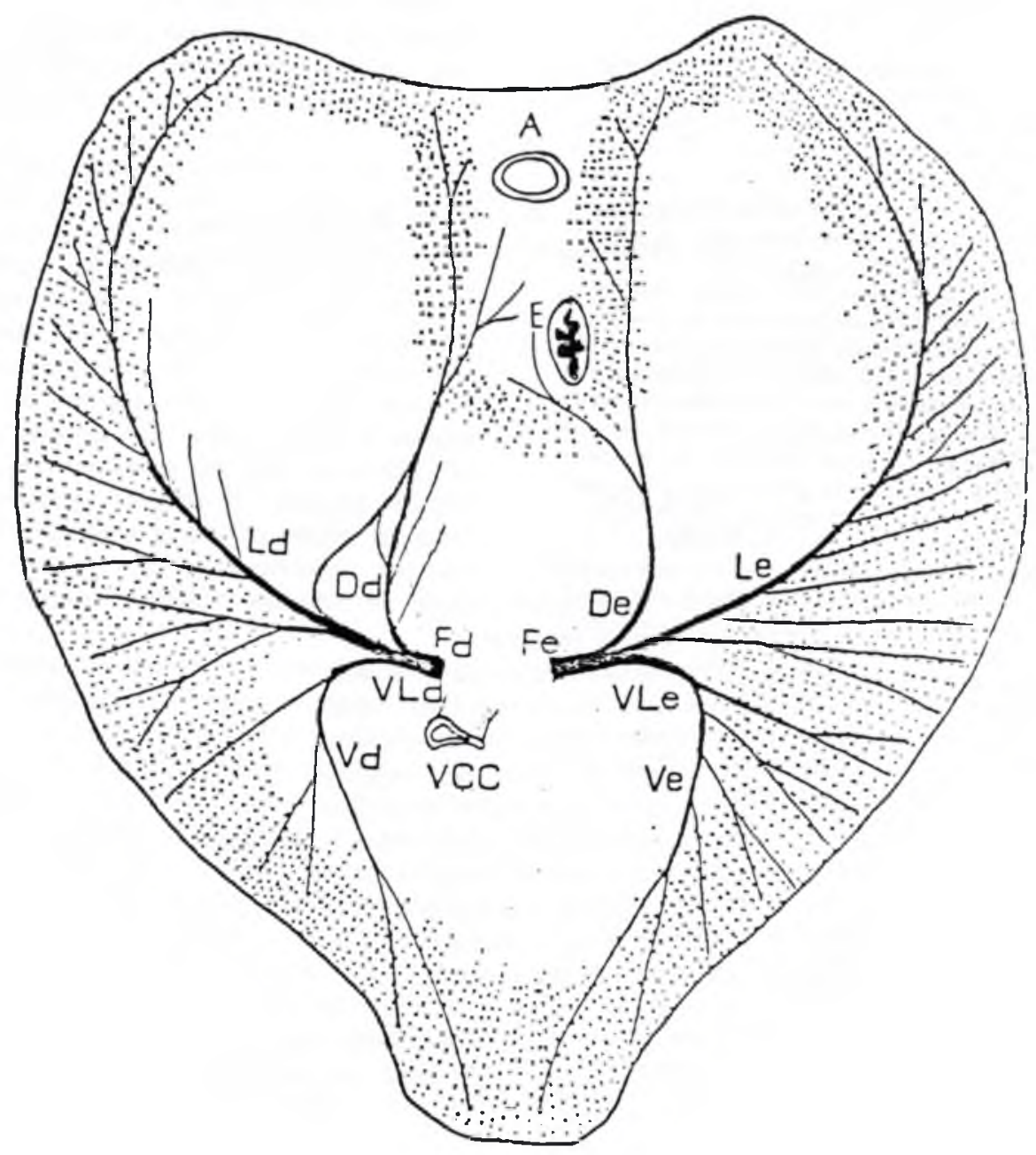

Figura 1 - Obs. $28 m$ 


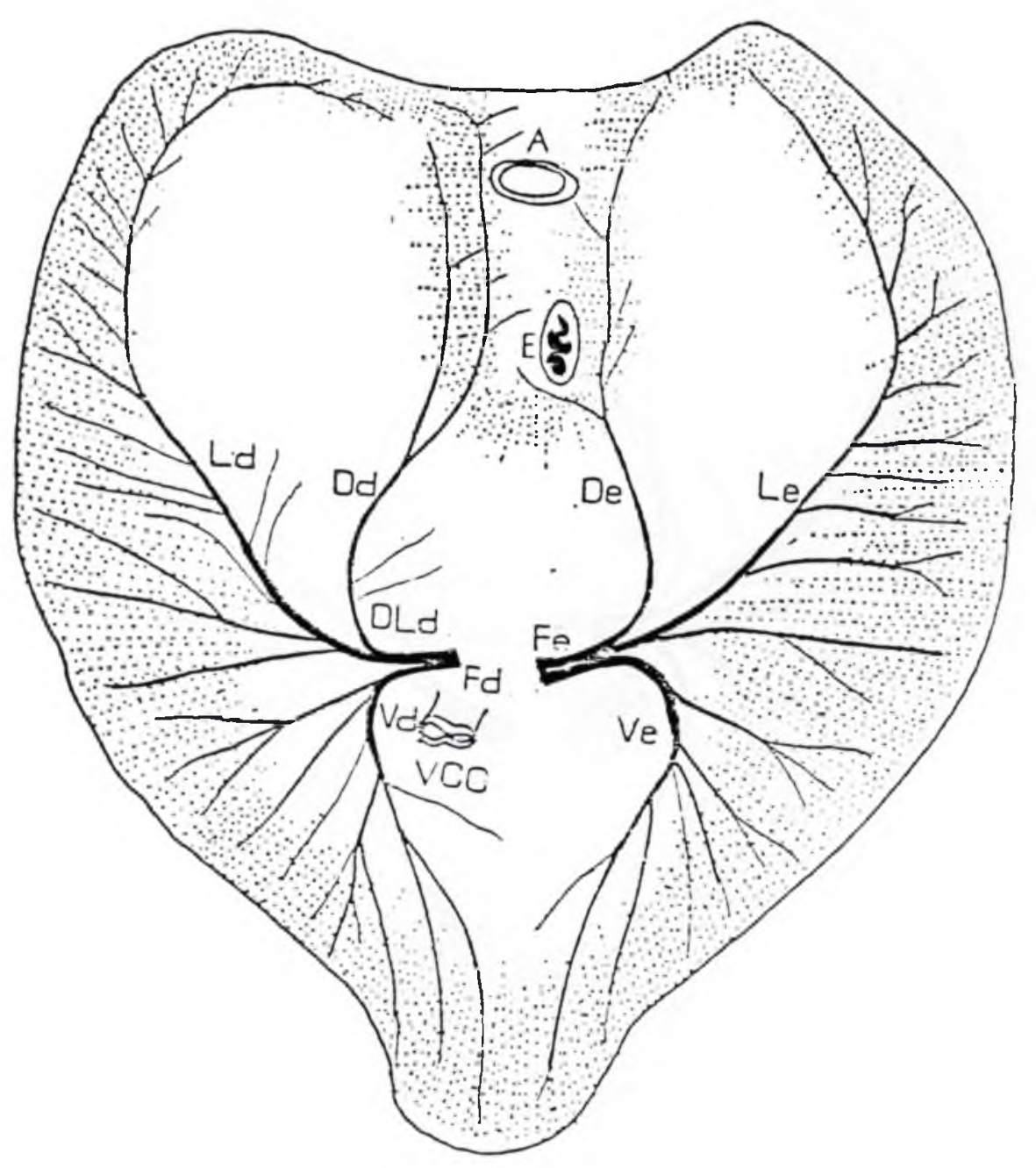

Figura 2 - Obs. $13 f$ 


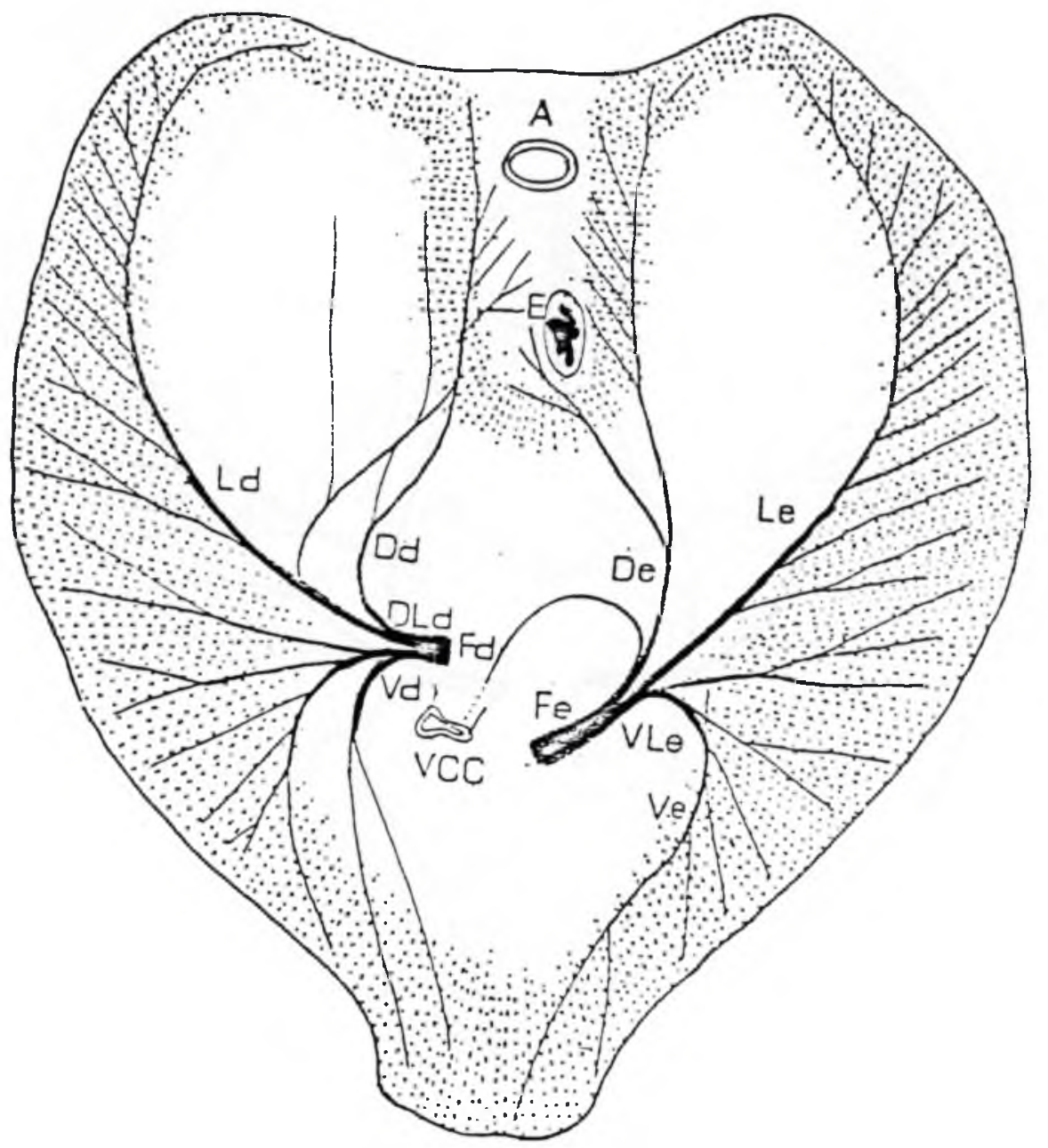

Figura 3 - Obs. $14 \mathrm{~m}$ 


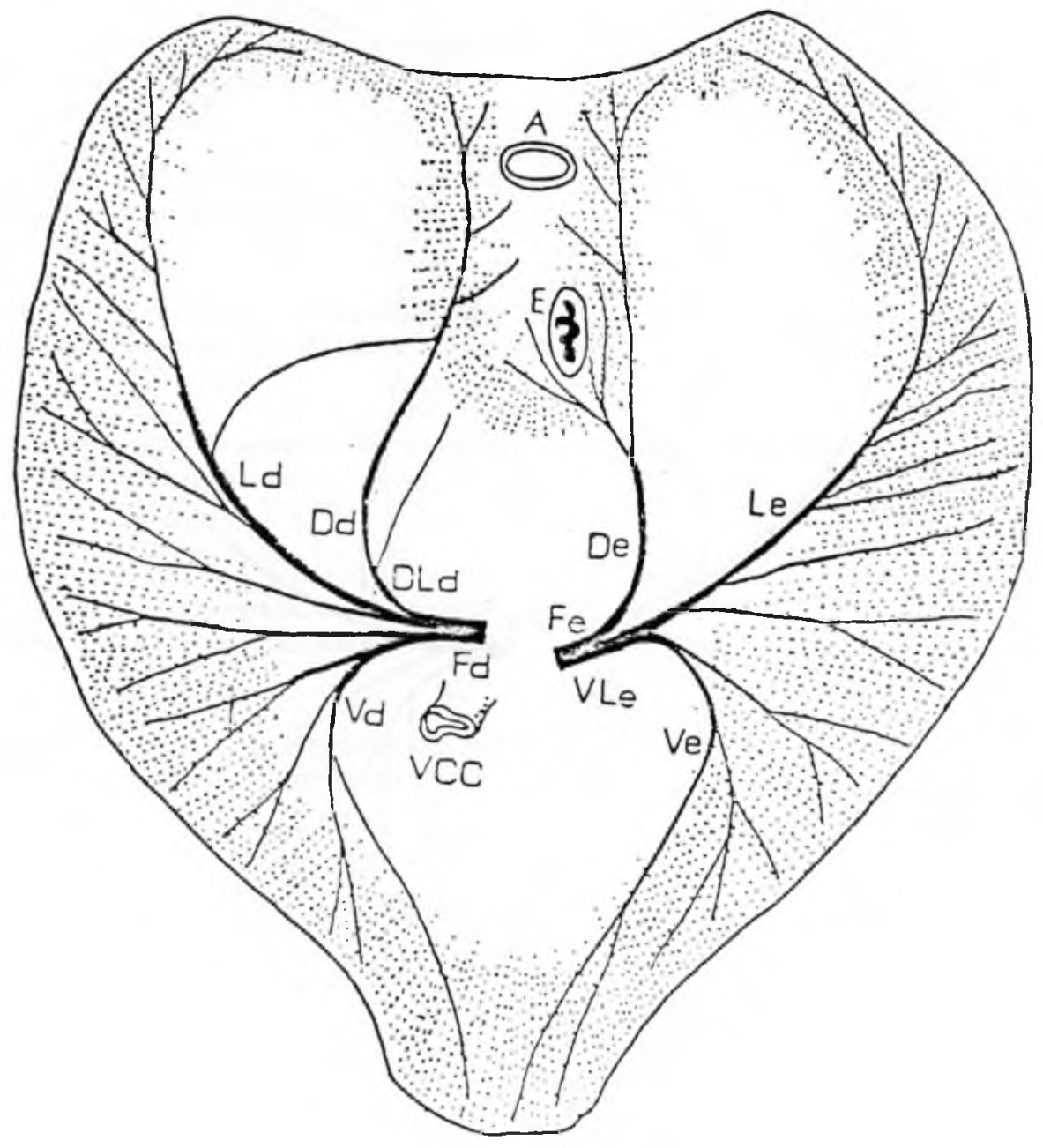

Figura 4 - Obs. $11 f$ 


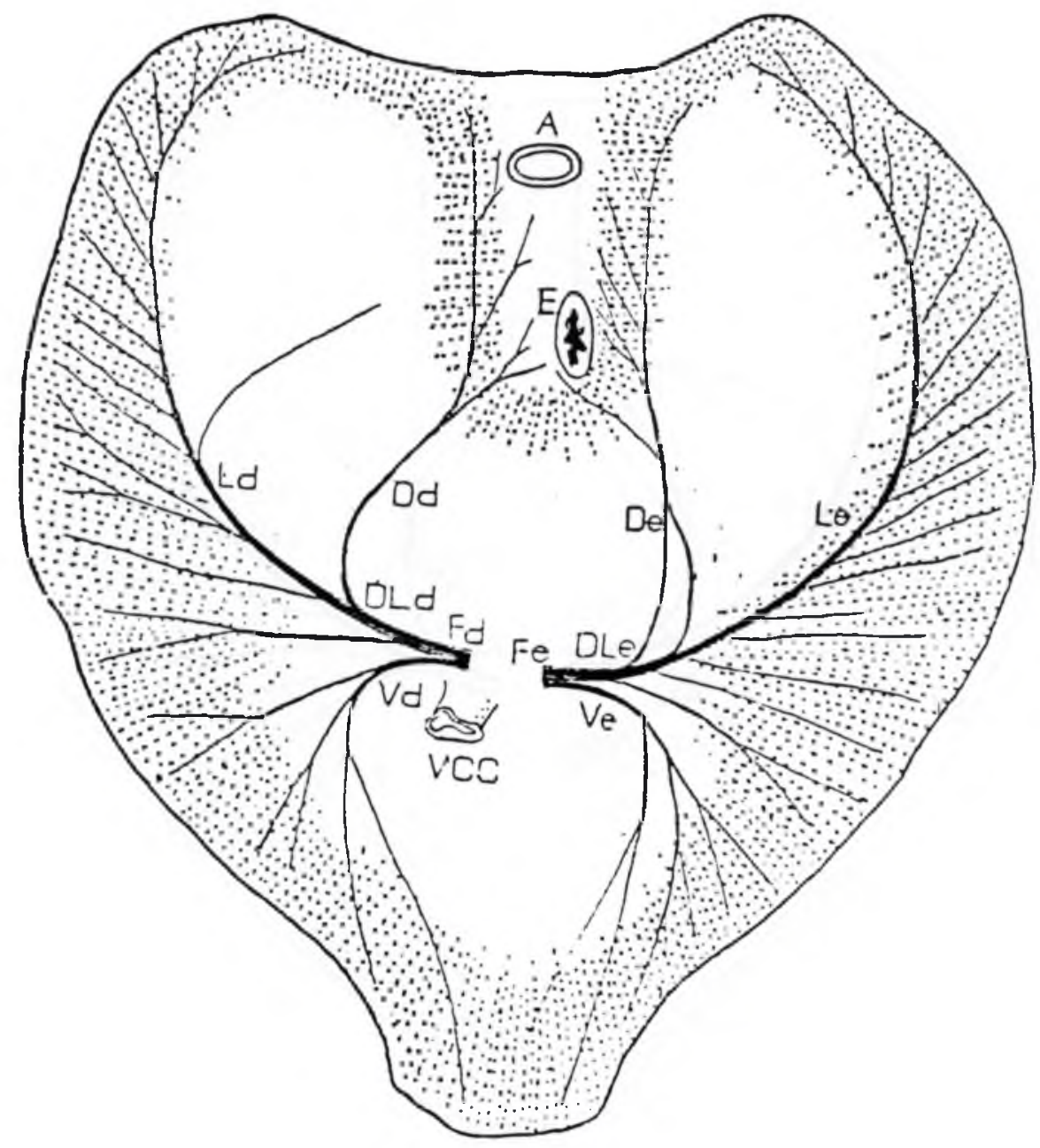

Figura 5 - Obs. $22 m$ 


\section{REFERÉNCIAS BIBLIOGRAFFICAS}

1 - BERTELLI, D. Ricerche sulla morfologia del muscolo diaframma nei mammiferi. Arch.Sci.med. 19. $381-436,1895$.

2 - BOSSI, V.; CARADONNA, G.B.; SPAMPANI, G.; VARALDI, L.; ZIMMERL, U. Trattato di ana tomia veterinaria. Milano, Francesco Vallardi, s.d. p. 228-9.

3- BRUNI, A.C. \& ZIMMERL, U. Anatomia degli animali domestici. Milano, Francesco Vallardi, 1947. p. 540.

4- DOBBERSTEIN, J. \& HOFFMANN, G. Lehrbuch der vergleichenden Aratomie der Haustiere. Leipzig, S. Hirzel, 1964. p. 166-7.

5 - ELLENBERger, W. \& BAUM, H. Handbuch der vergleichenden Anatomie der Haustiere. Berlin, Julius Springer, 1932. p. 904.

6 - GETTY, R. Sisson and Grossman's the anatomy of the domestic animals. 5.ed. Philadelphia, W.B. Saunders, 1975. v. 2, p. 11278.

7 - GONZALEZ y GARCIA, 'J.\& \&ONZALEZ ALVA. REZ, R. Anatomia comparada de los animales domesticos. Madrid, Gráfica Canales, 1961. p. 773 .

8 - GURLT'S, E.F. Handbuch der vergleichenden der Haussaugethiere. Berlin, August Hirschwald, 1873. p. 749 .
9 - LESBRE, F.X. Précis d'anatomie comparée des animaux domestiques. Paris, J.B. Baillière, 1923. p. 668-9.

10 - PANCRAZI, G. Sulla distribuzione del nervo frenico nel diafragma del mammiferi. Atti ist. Veneto Sci. Let. Art., 85(2) 1926 apud CONDE, R. Estudo anatômico, com dados experimentais sobre a distribuição dos nervos frênicos no músculo diafragma de Sus scrofa domesticus. Arq. Esc. Sup. Vet. Univ. Rural Est. M. Gerais, 12: 37-110, 1959.

11 - SCHWARZE, E. \& SCHRÖDER, L. Compendio de ana tomia veterinária. Zaragoza, Acribia, 1972. p. 65.

12 - SISSON, S. \& GROSSMANN, J.D. Anatomia de los animales domesticos. Barcelona, Salvat, 1959. p. 877-8.

13 - ZIMMERL, U. Anatomia topográfica veterinária. Milano, Francesco Vallardi, 1949. p. 255.

Recebido para publicação em 11-11-83 Aprovado para publicação em 15-03-84 